\title{
Longitudinal SPECT study in Alzheimer's disease: relation to apolipoprotein $\mathrm{E}$ polymorphism
}

M Lehtovirta, J Kuikka, S Helisalmi, P Hartikainen, A Mannermaa, M Ryynänen, P Sr Riekkinen, H Soininen

\begin{abstract}
Objectives-In mild Alzheimer's disease, SPECT imaging of regional cerebral blood flow has highlighted deficits in the posterior association cortex, and later in the disease process, the deficit spreads to involve the frontal cortex. The $\varepsilon 4$ allele of apolipoprotein $\mathrm{E}$ is a risk factor for Alzheimer's disease. The effect of apolipoprotein $E$ polymorphism on cerebral perfusion was studied. The hypothesis was that those patients with Alzheimer's disease who carry the $\varepsilon 4$ allele would have more severe cerebral hypoperfusion.

Methods-Thirty one patients with Alzheimer's disease and eight age and sex matched control subjects were examined in a three year longitudinal study. Patients with Alzheimer's disease were divided into subgroups according to their number of $\varepsilon 4$ alleles. Regional cerebral blood flow ratios referred to the cerebellum were examined by ${ }^{99 \mathrm{~m}}$ Tc-HMPAO SPECT. Apolipoprotein E genotypes were determined by digestion of polymerase chain reaction products with the restriction enzyme Hha1.
\end{abstract}

Results-All patients with Alzheimer's disease had bilateral temporoparietal hypoperfusion compared with control subjects. The two $\varepsilon 4$ allele subgroups had the lowest ratios at the baseline assessment in the parietal and occipital cortices, and at the follow up in the temporal, parietal, and occipital cortices. They had the highest reduction in percentage terms in the temporal and occipital cortices compared with the other subgroups. However, the global clinical severity did not differ at the baseline or follow up examinations between the subgroups.

Conclusion-Apolipoprotein E polymorphism is involved in the pathogenesis and heterogeneity of Alzheimer's disease as the most severe cerebral hypoperfusion was found in the $\varepsilon 4$ allele subgroups. This might have implications for therapeutic approaches in Alzheimer's disease.

(F Neurol Neurosurg Psychiatry 1998;64:742-746)

Keywords: Alzheimer's disease; apolipoprotein E; SPECT

Department of Neurology,

Kuopio University Hospital,

FIN 70211 Kuopio, Finland.

Fax 0035817173019

Received 2 June 1997 and in revised form 27 October 1997

Accepted 29 October 1997

Clinical, neurochemical, pathological, and genetic studies suggest that Alzheimer's disease is a heterogeneous entity. ${ }^{1-4}$ The $\varepsilon 4$ allele of apolipoprotein E is a risk factor for Alzheimer's disease and accelerates the onset of dementia..$^{5-8}$ The apolipoprotein $\mathrm{E}$ gene, located on chromosome 19, has three major alleles: $\varepsilon 2, \varepsilon 3$, and $\varepsilon 4$. Apolipoprotein $\mathrm{E}$ is present in senile plaques, neurofibrillary tangles, and cerebrovascular amyloid, the major neuropathological changes seen in Alzheimer's disease. Different binding properties of the apolipoprotein isoforms to $\beta$-amyloid and tau protein also suggests that it is involved in the pathogenesis of Alzheimer's disease. ${ }^{9}$ In addition, the extent of the deficit of acetylcholine containing neurons in brains of patients with Alzheimer's disease is related to the number of $\varepsilon 4$ alleles present. ${ }^{1011}$

Changes in the cerebral metabolism and perfusion can be detected by single photon emission computed tomography (SPECT). The decreased metabolism and reduced cerebral perfusion in Alzheimer's disease are known to occur predominantly in temporal and parietal areas, ${ }^{12-14}$ regions which show the greatest neurochemical postmortem abnormalities. ${ }^{15}$ It has been suggested that mildly affected patients show temporoparietal and some frontal changes, whereas more severely demented patients also show decreased blood flow in other regions - for example, the occipital areas. ${ }^{14}{ }^{16}$ In a recent PET study, subjects with age associated memory impairment, one $\varepsilon 4$ allele, and a family history of Alzheimer's disease had abnormally low and asymmetric rates of glucose metabolism in a preselected parietal region even before the onset of dementia. ${ }^{17}$ Another PET study on cognitively normal subjects, with a family history of Alzheimer's disease reported that the $\varepsilon 4$ homozygotes had significantly reduced rates of glucose metabolism in the same posterior cingulate, parietal, temporal, and prefrontal regions as seen in patients with probable Alzheimer's disease. $^{18}$

This study attempted to examine the role of apolipoprotein E polymorphism in Alzheimer's disease with perfusion SPECT included in a three year longitudinal follow up. Our hypothesis was that those patients with Alzheimer's disease carrying the $\varepsilon 4$ allele of apolipoprotein $\mathrm{E}$ would have more severe deficits in their cerebral perfusion compared with patients without any $\varepsilon 4$ alleles.

Patients and methods
We studied 31 patients fulfilling the NINCDSADRDA criteria of probable Alzheimer's disease ${ }^{19}$ and eight age and sex matched cognitively intact control subjects in a longitudinal 
Table 1 Clinical characteristics of control subjects and patients with Alzheimer's disease (AD) according to 84 allele

\begin{tabular}{llllll}
\hline \multicolumn{7}{c}{ Patients with $A D$} & & \\
\cline { 2 - 5 } & $\begin{array}{l}2 \varepsilon 4 \\
(n=8)\end{array}$ & $\begin{array}{l}1 \varepsilon 4 \\
(n=13)\end{array}$ & $\begin{array}{l}0 \varepsilon 4 \\
(n=10)\end{array}$ & $\begin{array}{l}\text { all } A D \\
(n=31)\end{array}$ & Controls $(n=8)$ \\
\hline Women/men & $3 / 5$ & $5 / 8$ & $6 / 4$ & $14 / 17$ & $5 / 3$ \\
Familial/sporadic & $3 / 5$ & $4 / 9$ & $7 / 3$ & $14 / 17$ & \\
Age (y) & $65(8)$ & $75(7)^{\star}$ & $70(11)$ & $71(9)$ & $74(5)^{\star}$ \\
Age at onset (y) & $59(8)$ & $69(7)^{\star}$ & $64(10)$ & $64(9)$ & \\
Duration (y) & $6(2)$ & $6(2)$ & $6(1)$ & $6(2)$ & $9(2)$ \\
Education (y) & $7(1)$ & $8(5)$ & $7(2)$ & $7(3)$ & $9(2)$ \\
MMSE base line & $21(3)$ & $22(4)$ & $23(4)$ & $22(4)$ & $28(2)^{\star \star \star}$ \\
MMSE follow up & $15(5)$ & $17(5)$ & $16(8)$ & $16(6)$ & $29(1)^{\star \star \star}$ \\
\hline
\end{tabular}

${ }^{\star} \mathrm{p}<0.05 v 2 \varepsilon 4$, ANOVA; ${ }^{\star \star \star} \mathrm{p}<0.001 v$ all other groups, ANOVA.

Values are expressed as mean (SD).

study, in which the follow up examination was three years after the baseline assessment. Table 1 presents their clinical characteristics. The patients with Alzheimer's disease were at the baseline either undergoing diagnostic examination or had been recently diagnosed. The ethics committee of the Kuopio University Hospital approved the study and all the subjects and caregivers of demented patients gave informed consent for participation in the study.

The patients with Alzheimer's disease underwent the following examinations: general physical and clinical neurological examination, assessment of clinical severity with mini mental state examination (MMSE) ${ }^{20}$ and brief cognitive rating scale (BCRS), ${ }^{21}$ assessment of extrapyramidal signs with the Webster scale, ${ }^{22}$ assessment of depressive symptoms by the Hamilton scale, ${ }^{23}$ neuropsychological tests, laboratory tests to exclude secondary causes of dementia, brain MRI and SPECT, conventional and quantitative EEG, and event related potentials. All patients with Alzheimer's disease scored less than 4 on the modified ischaemic scale. $^{24}$

\section{SINGLE PHOTON EMISSION COMPUTED}

TOMOGRAPHY

A dose of 370 to $555 \mathrm{MBq}$ 99m Tc-HMPAO (Amersham International, London, UK) was intravenously injected into a subject's vein in a dark and quiet room. High resolution SPECT was carried out with a three head Siemens MultiSPECT 3 gamma camera equipped with high resolution collimators. ${ }^{25}$ Ten minutes after injection of the tracer, the radioactivity distribution of the brain was acquired in a $128 \times 128$ matrix mode. Data sets were acquired at $3^{\circ}$ intervals for 35 seconds each, with a total of 40 sets $\left(120^{\circ}\right.$ per camera head). Three and a half millimeter thick transaxial (oriented in orbitomeatal line), sagittal, and coronal slices were reconstructed using a Butterworth filter (a cut off frequency of $0.5 \mathrm{~cm}^{-1}$ ) and a uniform attenuation correction of $0.12 \mathrm{~cm}^{-1}$. The imaging resolution was $8-9 \mathrm{~mm} .{ }^{25}$ Two consecutive slices were summed to obtain a slice thickness of $7 \mathrm{~mm}$ and visually surveyed on a TV screen. A semiautomatic brain quantification program of Siemens Gammsonics Inc (Hofman, IL, USA) was used to analyse the regions of interest. Firstly, the slices were rotated and realigned so that transaxial ( $\mathrm{x}$ direction), sagittal (y direction), and coronal ( $\mathrm{z}$ direction) ones were in $90^{\circ}$ angles to each other. Secondly, the regions of interest were drawn on to aligned transaxial slices on the right and then mirrored on the left. The method has been described earlier in detail. ${ }^{26}$ Regional count densities (regional cerebral blood flow) were calculated for frontal, temporal, parietal, and occipital cortices. The regional counts were related to the cerebellar counts and regional cerebral blood flow is expressed as this ratio for each region. Cerebellum was used to normalise the other cortical areas, because it is generally spared by major pathological involvement. ${ }^{27}$ The rater was not aware of the clinical data of the subjects.

DETERMINATION OF APOLIPOPROTEIN E GENOTYPE

DNA was prepared from blood leucocytes of patients with Alzheimer's disease by standard procedures. Apolipoprotein E genotypes were analysed using the polymerase chain reaction (PCR) described earlier ${ }^{28}$ with minor modifications. ${ }^{30}$ Apolipoprotein $\mathrm{E}$ genotypes were identified through HhaI digestion. Digested DNA fragments were analysed via polyacrylamide gel electrophoresis and separated fragments of DNA were visualised by staining with ethidium bromide.

STATISTICAL ANALYSIS OF DATA

The data were analysed using SPSS for Windows version 6.1.3. software. We used analysis of variance (ANOVA) to detect differences in means over the study groups at the baseline and the follow up examination. The Duncan method was applied in post hoc analysis when appropriate. Multivariate analysis for repeated measures (MANOVA) with Bonferroni's correction was used to detect the change in perfusion ratios over time between the study groups. Patients with Alzheimer's disease were divided into three subgroups according to the number of apolipoprotein $\mathrm{E}$ alleles; two $\varepsilon 4$ alleles, one $\varepsilon 4$ allele, and no $\varepsilon 4$ alleles. A $\chi^{2}$ test was used for evaluation of the categorical data. The level of significance was set at $\mathrm{p}<0.05$.

\section{Results}

Patients with Alzheimer's disease and control subjects did not differ in age, education, or sex. Alzheimer's disease subgroups had a similar duration of dementia and equal clinical severity as assessed with MMSE at the baseline and follow up, the decline in MMSE was about six points in three years. However, the homozygous $\varepsilon 4$ allele subgroup had an earlier onset of the disease and was younger than the other subgroups (table 1).

Cerebral perfusion ratios measured with SPECT for all patients with Alzheimer's disease were significantly reduced in temporoparietal regions compared with control subjects. Moreover, some differences were evident in the perfusion ratios for subgroups of Alzheimer's disease. The homozygous $\varepsilon 4$ allele subgroup had the lowest ratios at the baseline in the parietal and occipital cortices, and at the follow up in the temporal, parietal, and occipital cortices. The difference was significant at the follow up in the right and left occipital 
Table 2 Regional cerebral blood flow related to cerebellum: control subjects and subgroups with Alzheimer's disease (AD) according to the number of the $\varepsilon 4$ alleles

\begin{tabular}{|c|c|c|c|c|c|}
\hline & \multicolumn{4}{|c|}{ Patients with $A D$} & \multirow[b]{2}{*}{ Control subjects $(n=8)$} \\
\hline & $2 \varepsilon 4(n=8)$ & $1 \varepsilon 4(n=13)$ & $0 \varepsilon 4(n=10)$ & all $A D(n=31)$ & \\
\hline \multicolumn{6}{|c|}{ Right frontal cortex: } \\
\hline Baseline & $0.87(0.07)$ & $0.89(0.09)$ & $0.84(0.10)$ & $0.87(0.09)$ & $0.87(0.07)$ \\
\hline Follow up & $0.81(0.11)$ & $0.85(0.10)$ & $0.76(0.15)$ & $0.81(0.12)$ & $0.89(0.05)$ \\
\hline \multicolumn{6}{|c|}{ Left frontal cortex: } \\
\hline Baseline & $0.83(0.09)$ & $0.85(0.10)$ & $0.80(0.12)$ & $0.83(0.10)$ & $0.85(0.03)$ \\
\hline Follow up & $0.79(0.10)$ & $0.81(0.10)$ & $0.72(0.17)$ & $0.78(0.13)$ & $0.85(0.07)$ \\
\hline \multicolumn{6}{|c|}{ Right temporal cortex: } \\
\hline Baseline & $0.85(0.04)^{\star}$ & $0.84(0.05)^{\star}$ & $0.86(0.04)^{\star}$ & $0.85(0.04)^{\star}$ & $0.90(0.04)$ \\
\hline Follow up & $0.78(0.06)$ & $0.81(0.08)$ & $0.84(0.10)$ & $0.81(0.06)^{\star}$ & $0.88(0.06)$ \\
\hline \multicolumn{6}{|c|}{ Left temporal cortex: } \\
\hline Baseline & $0.80(0.08)$ & $0.82(0.07)$ & $0.80(0.12)$ & $0.81(0.09)^{\star}$ & $0.88(0.05)$ \\
\hline Follow up & $0.73(0.09)$ & $0.77(0.11)$ & $0.77(0.14)$ & $0.76(0.11)^{\star}$ & $0.85(0.04)$ \\
\hline \multicolumn{6}{|c|}{ Right parietal cortex: } \\
\hline Baseline & $0.80(0.06)$ & $0.84(0.07)$ & $0.84(0.04)$ & $0.83(0.06)^{\star}$ & $0.88(0.04)$ \\
\hline Follow up & $0.76(0.05)^{\star}$ & $0.79(0.08)^{\star}$ & $0.79(0.10)^{\star}$ & $0.78(0.05)^{\star}$ & $0.88(0.05)$ \\
\hline \multicolumn{6}{|c|}{ Left parietal cortex: } \\
\hline Baseline & $0.75(0.08)$ & $0.80(0.08)$ & $0.81(0.10)$ & $0.79(0.09)^{\star}$ & $0.86(0.04)$ \\
\hline Follow up & $0.72(0.07)^{\star}$ & $0.73(0.10)^{\star}$ & $0.75(0.13)^{\star}$ & $0.73(0.10)^{\star}$ & $0.87(0.04)$ \\
\hline \multicolumn{6}{|c|}{ Right occipital cortex: } \\
\hline Baseline & $0.91(0.08)$ & $0.93(0.07)$ & $0.95(0.06)$ & $0.93(0.07)$ & $0.92(0.04)$ \\
\hline Follow up & $0.84(0.10) \dagger^{\star}$ & $0.89(0.06)$ & $0.95(0.06)$ & $0.90(0.08)$ & $0.94(0.05)$ \\
\hline \multicolumn{6}{|c|}{ Left occipital cortex: } \\
\hline Baseline & $0.88(0.09)$ & $0.90(0.08)$ & $0.96(0.07)$ & $0.92(0.08)$ & $0.91(0.07)$ \\
\hline Follow up & $0.82(0.07) \dagger^{\star}$ & $0.86(0.10) \dagger$ & $0.94(0.07)$ & $0.87(0.10)$ & $0.92(0.05)$ \\
\hline
\end{tabular}

${ }^{\star} \mathrm{p}<0.05 v$ controls, $\dagger v 0 \varepsilon 4$ subgroup, ANOVA

Values are expressed as mean (SD).

cortices compared with the no $\varepsilon 4$ allele subgroup and control subjects. Also, at the follow up, the one $\varepsilon 4$ allele subgroup had a significantly reduced perfusion ratio in the left occipital cortex compared with the no $\varepsilon 4$ allele subgroup (table 2).

Multivariate analysis of variance for repeated tests showed a significant effect of the three year follow up time on all regions studied. A significant interaction effect of time and different apolipoprotein $\mathrm{E}$ groups was found in the right occipital cortex and the left parietal cortex. In the right occipital cortex, the perfusion ratio was significantly reduced in the homozygous $\varepsilon 4$ allele subgroup compared with the no $\varepsilon 4$ allele subgroup and in the left parietal cortex in the one $\varepsilon 4$ allele subgroup compared with the control subjects (figure). The figure 1 shows, in percentage terms, the change be-

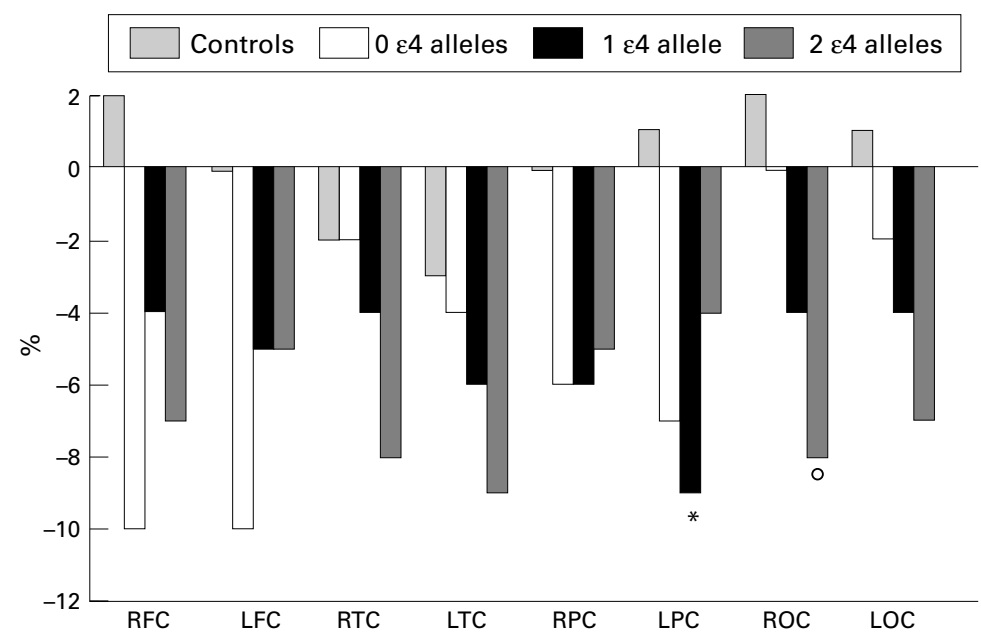

Percentage changes between the baseline and the follow up examinations in control subjects and the subgroups with Alzheimer's disease according to the number of the 44 alleles. $R F C=$ right frontal cortex; $L F C=$ left frontal cortex; $R T C=$ right temporal cortex; $L T C=$ left temporal cortex; $R P C=$ right parietal cortex $[P C=$ left parietal cortex; $R O C=$ right occipital cortex; LOC=left occipital cortex. MANOVA $p<0.05$. ${ }^{\star}$ Differs from control subjects; $o$ differs from no 44 subgroup. tween the baseline and follow up examination in the different study groups. The homozygous $\varepsilon 4$ allele subgroup had the highest reduction in the perfusion ratios in the temporal and the occipital cortices compared with the other subgroups.

\section{Discussion}

Patients with Alzheimer's disease show cerebral hypoperfusion, mainly in the temporal and parietal cortices, ${ }^{12-14}$ but $15 \%-20 \%$ of patients also show hypoperfusion in the frontal cortices. $^{3132}$ Occipital areas have been used as reference regions for normalising perfusion values, although PET and a few SPECT studies have also shown occipital changes in patients with Alzheimer's disease. ${ }^{14} 33$ In our three year longitudinal study, patients with Alzheimer's disease had decreased perfusion ratios in the parietal and temporal regions compared with the control subjects. When patients with dementia were divided into subgroups according to the $\varepsilon 4$ allele, the homozygous $\varepsilon 4$ allele subgroup had the lowest perfusion ratios in the parietal and occipital cortices at the baseline, and at the follow up this was evident also in the temporal cortices. The $\varepsilon 4$ allele of apolipoprotein $\mathrm{E}$ is a well established risk factor for Alzheimer's disease. In both patients with Alzheimer's disease and non-demented elderly subjects, memory functions and medial temporal lobe structures, such as the hippocampus, seem to be particularly vulnerable to the deleterious effects of the \&4 allele of apolipoprotein E. ${ }^{29}{ }^{35-37}$ Two PET studies in non-demented relatives at risk for familial dementia showed reduced rates of glucose metabolism in the same regions where this occurs in patients with Alzheimer's disease. ${ }^{17}{ }^{18}$ These findings suggest that identification of $\varepsilon 4$ homozygous subjects with memory impairment might help to identify those at highest 
risk for dementia, and locate a possible group for treatment strategies to prevent the disease.

The homozygous $\varepsilon 4$ subgroup had the greatest reduction in percentage terms in the follow up in the temporal and occipital cortices compared with other subgroups (figure). An earlier two year longitudinal SPECT study reported that the decreases in regional cerebral function, compared with control values varied from $1 \%$ to $4.2 \%$ in the different regions. ${ }^{38}$ In our three year follow up study, the perfusion values for all patients with Alzheimer's disease compared with controls, decreased on average, between $2.4 \%$ and $9 \%$. In our study, at the baseline and follow up examinations, the extent of global disease was equally severe in the Alzheimer subgroups. Moreover, the homozygous $\varepsilon 4$ allele subgroup did not differ from other subgroups in visuospatial functions as examined with a copy a cube and clock setting test ${ }^{39}$ and the block design subtest of the Wechsler adult intelligence scale. ${ }^{40}$ However, the homozygous $\varepsilon 4$ allele subgroup had the lowest scores on immediate and delayed tests assessing verbal and visual memory. Verbal memory was examined with a list learning test using shopping items ${ }^{41}$ and the Wechsler logical memory test using one story. ${ }^{42}$ Visual memory was examined with the Heaton visual reproduction test. ${ }^{43}$ The delayed recall of the story and the figures and a yes/no recognition of the words in the list were asked after a 30 minute delay filled with other psychometric tests. Occipital hypoperfusion is only occasionally found in most studies of Alzheimer's disease. Recently, a PET study of three patients with pathologically verified pure diffuse Lewy body disease and three patients with combined Lewy body and Alzheimer's disease pathology disclosed pronounced declines in association and primary somatomotor cortices in both groups. However, the patients with pure Lewy body disease also exhibited hypometabolism in the occipital association and primary visual cortex. ${ }^{44}$ Patients with Lewy body disease are thought to have a more severe cholinergic deficit than patients with Alzheimer's disease. ${ }^{45}$ Also, recent data suggest that the magnitude of the cholinergic depletion is greater in $\varepsilon 4$ homozygous patients with Alzheimer's disease. ${ }^{11}{ }^{11}$ The cerebral blood flow is regulated by cholinergic, noradrenergic, and serotonergic pathways. ${ }^{46}$ As the density of cholinergic innervation is lower in the primary sensory areas - such as the occipital cortex - than in associative cortical regions and limbic structures ${ }^{47}$ it is possible that the more severe cholinergic depletion in the $\varepsilon 4$ homozygotes may be reflected in early phases as hypoperfusion in those regions with reduced cholinergic innervation.

In conclusion, we found that the homozygous $\varepsilon 4$ patients with Alzheimer's disease had the lowest cerebral perfusion in the temporal, parietal, and occipital cortices compared with those patients with Alzheimer's with one or no $\varepsilon 4$ alleles. Apolipoprotein E polymorphism seems to be a major contributor to the heterogeneity of Alzheimer's disease, and this might have implications for therapeutic approaches in this disorder.

This study was supported by grant from the Health Research Council of the Academy of Finland and the North Savo Regional Fund of the Finnish Cultural Foundation.

1 Rossor M, Iversen L, Reynolds G. Neurochemical characeristics of early and late onset types of Alzheimer's disease. BMF 1984;288:961-4.

2 Mayeux R, Stern Y, Spanton S. Heterogeneity in dementia of the Alzheimer type: evidence of subgroups. Neurology 1985;35:453-61.

3 Rossor M. Molecular pathology of Alzheimer's disease. $\mathcal{f}$ Neurol Neurosurg Psychiatry 1993;56:583-6.

4 Sandbrink R, Hartmann T, Masters CL, et al. Genes contributing to Alzheimer's disease. Molecular Psychology 1996;1:27-40.

5 Corder EH, Saunders AM, Strittmatter WJ, et al. Gene dose of apolipoprotein E type 4 allele and the risk of Alzheimer's disease in late onset families. Science 1993;261:921-3.

6 Mayeux R, Stern Y, Ottman R, et al. The apolipoprotein 4 allele in patients with Alzheimer's disease. Ann Neurol 1993;34:752-4.

7 Saunders A, Strittmatter W, Schmechel D, et al. Association of apolipoprotein E allele 4 with late-onset familial and
sporadic Alzheimer's disease. Neurology 1993;43:1467-72.

8 Lehtovirta M, Helisalmi S, Mannermaa A, et al. Apolipoprotein E polymorphism and Alzheimer's disease in eastern Finland. Neurosci Lett 1995;185:13-5.

9 Strittmatter WJ, Weisgraber $\mathrm{KH}$, Goedert $\mathrm{M}$, et al. Hypothesis: microtubule instability and paired helical filament formation in the Alzheimer disease brain are related to apolipoprotein E genotype. Exp Neurol 1994;125: 163-71.

10 Poirier J. Apolipoprotein E in animal models of CNS injury and in Alzheimer's disease. TINS 1994;17:525-30.

1 Soininen $\mathrm{H}$, Kosunen $\mathrm{O}$, Helisalmi S, et al. A severe loss of choline acetyltransferase in the frontal cortex of Alzheimer patients carrying apolipoprotein 4 allele. Neurosci Lett 1995;187:79-82.

12 Burns A, Philpot M, Costa D, et al. The investigation of Alzheimer's disease with single photon emission tomography. F Neurol Neurosurg Psychiatry 1989;52:248-53.

13 Liu H-C, Liu R-S, Lin K-N, et al. Single photon emission Liu H-C, Liu R-S, Lin K-N, et al. Single photon emission
computed tomography using ${ }^{99} \mathrm{Tcm}-\mathrm{HMPAO}$ in Alzheimer's disease. Nucl Med Commun 1992;13:535-41.

14 O'Brien JT, Eagger S, Syed GMS, et al. A study of regional cerebral blood flow and cognitive performance in Alzheimer's disease. F Neurol Neurosurg Psychiatry 1992;55:1182-7.

5 Najlerahim A, Bowen D. Biochemical measurements in Alzheimer's disease reveal a necessity for improved neuroimaging techniques to study metabolism. Biochem $\mathcal{f}$ 1988;251:305-8.

16 Eberling JL, Jagust WJ, Reed BR, et al. Reduced temporal lobe blood flow in Alzheimer's disease. Neurobiol Aging 1992;13:483-91.

17 Small GW, Mazziotta JC, Collins MT, et al. Apolipoprotein E type 4 allele and cerebral glucose metabolism in relatives at risk for familial Alzheimer disease. $\mathscr{F} A M A$ 1995;273: 942-7.

18 Reiman EM, Caselli RJ, Yun LS, et al. Preclinical evidence of Alzheimer's disease in persons homozygous for the $\varepsilon 4$ allele for apolipoprotein E. N Engl f Med 1996;334:752-8.

19 McKhann G, Drachman D, Folstein M, et al. Clinical diagMcKhann G, Drachman D, Folstein M, et al. Clinical diag-
nosis of Alzheimer's disease. Report of the NINCDSADRDA work group under the auspices of Department of Health and Human Services Task Force on Alzheimer's disease. Neurology 1984;34:939-44

20 Folstein MF, Folstein SE, McHugh PR. Mini-mental state: a practical method for grading the cognitive state of patients for the clinician. F Psychiatr Res 1975;12:189-98.

21 Reisberg B, Schneck MK, Ferris SH. The brief cognitive rating scale (BCRS): findings in primary degenerative dementia (PDD). Psychopharmacol Bull 1983;19:734-9.

22 Webster DD. Clinical analysis of the disability on Parkinson's disease. Mod Treat 1968;5:257-62.

23 Hamilton M. A rating scale for depression. $\mathcal{F}$ Neurol Neurosurg Psychiatry 1960;23:56-62.

24 Rosen WG, Terry RD, Fuld PA, et al. Pathological verification of ischemic score in differentiation of dementias. Ann Neurol 1980;7:486-8. Kuikka J, Tenhunen-Eskelinen M, Jurvelin J, et al. Physical
performance of the Siemens multiSPECT 3 gamma performance of the Siemens multiSPEC
camera. Nucl Med Commun 1993;14:490-7.

26 Soininen H, Helkala E-L, Kuikka J, et al. Regional cerebral blood flow measured by ${ }^{99 m}$ Tc-HMPAO SPECT differs in subgroups of Alzheimer's disease. F Neural Transm Park Dis Dement Sect 1995;9:95-109.

27 Brun A, Englund E. Regional pattern of degeneration in Alzheimer's disease: neuronal loss and histopathological grading. Histopathology 1981;5:549-64.

28 Hixon JE, Vernier DT. Restriction isotyping of human apolipoprotein $\mathrm{E}$ by gene amplification and cleavage with HhaI. f Lipid Res 1990;31:545-8.

29 Tsukamoto K, Watanabe T, Matsushima T, et al. Determination by PCR-RFLP of apoE genotype in a Japanese nation by PCR-RFLP of apoE genotype in

30 Lehtovirta M, Laakso MP, Soininen H, et al. Volumes of hippocampus, amygdala and frontal lobe in Alzheimer patients with different apolipoprotein E genotypes. Neuroscience 1995;67:65-72. 
31 Johnson K, Mueller S, Walshe T, et al. Cerebral perfusion imaging in Alzheimer's disease. Arch Neurol 1987;44:165-

32 Perani D, Di Piero V, Vallar G, et al. Technetium-99m HM-PAO-SPECT study of regional cerebral perfusion in early Alzheimer's disease. F Nucl Med 1988;29:1507-14.

33 Frackowiak R, Pozzilli C, Legg N, et al. Regional cerebra oxygen supply and utilisation in dementia. Brain 1981;104 753-78.

34 Habert M, Spampinato U, Mas J, et al. A comparative technetium $99 \mathrm{~m}$ hexamethylpropylene amine oxime SPET study in different types of dementia. Eur F Nucl Med 1991; 18:3-11.

35 Reed T, Carmelli D, Swan G, et al. Lower cognitive performance in normal older adult male twins carrying the apolipoprotein E 4 allele. Arch Neurol 1994;51:1189-92.

36 Bondi MW, Salmon DP, Monsch AU, et al. Episodic memory changes are associated with the APOE- $\varepsilon 4$ allele in memory changes are associated with the APOE- $\varepsilon 4$ allele
non-demented older adults. Neurology 1995;45:2203-6.

37 Soininen H, Partanen K, Pitkänen A, et al. Volumetric MRI analysis of the amygdala and the hippocampus in subjects with age-associated memory impairment: correlation to with age-associated memory impairment: correlation
visual and verbal memory. Neurology 1994;44:1660-8.

38 Brown DRP, Hunter R, Wyper R, et al. Longitudinal changes in cognitive function and regional cerebral function in Alzheimer's disease: a SPECT blood flow study. f Psychiatr Res 1996;30:109-26.
39 Goodglass $\mathrm{H}$, Kaplan E. The assessment of aphasia and related disorders. Philadelphia: Lea and Febiger, 1983.

40 Wechsler D. WAIS-R manual. New York: Psychological Corporation, 1981.

41 Helkala E-L, Laulumaa V, Soininen H, et al. Recall and recognition on memory in patients with Alzheimer's and Parkinson's diseases. Ann Neurol 1988;24:214-7.

42 Wechsler D. A standardised memory scale for clinical use. $\mathcal{F}$ Psychol 1945;19:87-95.

43 Russell EW. A multiple scoring method for assessment of complex memory functions. F Consult Clin Psychol 1975;43: $800-9$.

44 Albin RL, Minoshima S, D'Amato CJ, et al. Fluorodeoxyglucose positron emission tomography in diffuse Lewy-body disease. Neurology 1996;47:462-6.

45 Perry EK, Haroutunian V, Davis KL, et al. Neocortical cholinergic activities differentiate Lewy body dementia from classical Alzheimer's disease. Neuroreport 1994;5:7479.

46 Sato A, Sato Y. Regulation of regional cerebral blood flow by cholinergic fibers originating in the basal forebrain. Neurosci Res 1992;14:242-74.

47 McCormick DA. Cellular mechanisms of cholinergic control of neocortical and thalamic neuronal excitability. In: Steriade M, Biesold D, eds. Brain cholinergic systems. New York: University Press, 1990:236-64. 